\title{
Giant Intracranial Arachnoid Cyst Causing Acute Neurologic Symptoms
}

\author{
Youssouf Sogoba1, Boubacar Sogoba1, Seybou Hassane Diallo², Drissa Kanikomo', \\ Djenè Kourouma', Oumar Coulibaly ${ }^{3}$, Issa Amadou ${ }^{4}$, Moustapha Manganés, \\ Hamidou Almeimoune ${ }^{5}$, Madani Thierno Diop5, Youssoufa Maiga², \\ Broulaye Samaké5, Djibo M. Diango ${ }^{5}$
}

\footnotetext{
${ }^{1}$ Department of Neurosurgery, Hôpital Gabriel Touré, Bamako, Mali

${ }^{2}$ Department of Neurology, Hôpital Gabriel Touré, Bamako, Mali

${ }^{3}$ Department of Neurosurgery, Hôpital du Mali, Bamako, Mali

${ }^{4}$ Department of Pediatric Surgery, Hôpital Gabriel Touré, Bamako, Mali

${ }^{5}$ Department of Anesthesiology and ICU, Hôpital Gabriel Touré, Bamako, Mali

Email: sogobayoussouf@yahoo.fr
}

How to cite this paper: Sogoba, Y., Sogoba, B., Diallo, S.H., Kanikomo, D., Kourouma, D., Coulibaly, O., Amadou, I., Mangané, M., Almeimoune, H., Diop, M.T., Maiga, Y., Samaké, B. and Diango, D.M. (2018) Giant Intracranial Arachnoid Cyst Causing Acute Neurologic Symptoms. World Journal of Neuroscience, 8, 363-369.

https://doi.org/10.4236/wins.2018.83029

Received: July 24, 2018

Accepted: August 11, 2018

Published: August 14, 2018

Copyright (c) 2018 by authors and Scientific Research Publishing Inc. This work is licensed under the Creative Commons Attribution International License (CC BY 4.0).

http://creativecommons.org/licenses/by/4.0/

\begin{abstract}
Intracranial arachnoid cysts (IAC) are benign lesions containing cerebrospinal fluid (CSF). Most of them are clinically silent and remain static in size. However some may present with mild and slow progressive symptoms caused by the cyst. The authors present the case of 54-year-old woman who presented with acute symptoms of severe headache, vomiting, and gait disturbance of 2 day's duration. She had no history of head trauma. On admission, neurological examination revealed that the patient had a Glasgow Coma Scale score of 15, and a left side hemiplegia. A CT scan revealed a hypodense fluid collection in the right frontoparietal region that mimicked an arachnoid cyst. The symptoms were improved after an emergency marsupialisation via craniotomy.
\end{abstract}

\section{Keywords}

Arachnoid Cyst, Neuroendoscopy, Microsurgical Fenestration

\section{Introduction}

Intracranial arachnoid cysts (IAC) are benign lesions containing cerebrospinal fluid (CSF). Most of them are congenital but acquired cases have been described after trauma, infection or skull base surgery [1] [2] [3] [4]. Arachnoid cysts comprise $1 \%$ of all intracranial space-occupying lesions [5]. The prevalence in adults is approximately $1.4 \%$ with a female preponderance, while the prevalence 
in children is 2.6\% [6] [7] [8]. Most patients with IAC are asymptomatic but some may develop symptoms such as macrocephaly, localized cranial bulging, increased intracranial pressure, seizures, focal neurological deficits, psychomotor retardation, headache and endocrine alterations [9] [10] [11]. The indication for surgical treatment is therefore challenging in the case of the most common symptoms associated with arachnoid cysts [6] [12]. There has been no consensus on the single best management strategy of Giant ICA. The most frequently used methods for treating arachnoid cysts are microsurgical fenestration via craniotomy, neuroendoscopic fenestration and cystoperitoneal shunting [13] [14] [15].

In this paper, the authors report the case of a Giant ICA with acute neurologic symptoms. The patient's clinical condition improved quickly after an emergency marsupialisation via craniotomy.

\section{Case Report}

This Malian 54-year-old woman was admitted to our neurosurgical department with acute symptoms of severe headache, vomiting, and gait disturbance of 2 day's duration. She had no history of head trauma. On admission, neurological examination revealed that the patient had a Glasgow Coma Scale score (GCS) of 15, and a left side hemiplegia. Results of routine laboratory studies were normal. A CT scan (Figure 1) revealed a hypodense fluid collection in the right frontoparietal region that mimicked an arachnoid cyst. An emergency surgery was done. A right frontoparietal craniotomy was performed. When the dura was opened, a typical arachnoid cyst was discovered. The cyst was widely marsupialized (Figure 2), the dura was closed and the craniotomy was repaired. The postoperative course was favorable. The patient's clinical condition improved quickly after surgery. The postoperative CT scan (Figure 3) showed complete resolution of the CSF collection. She was discharged home one week after the operation with GCS of 15 and was able to walk without assistance 3 weeks later.

\section{Discussion}

Bright [16] first described IAC in 1831. IAC are congenital lesions of the arachnoid

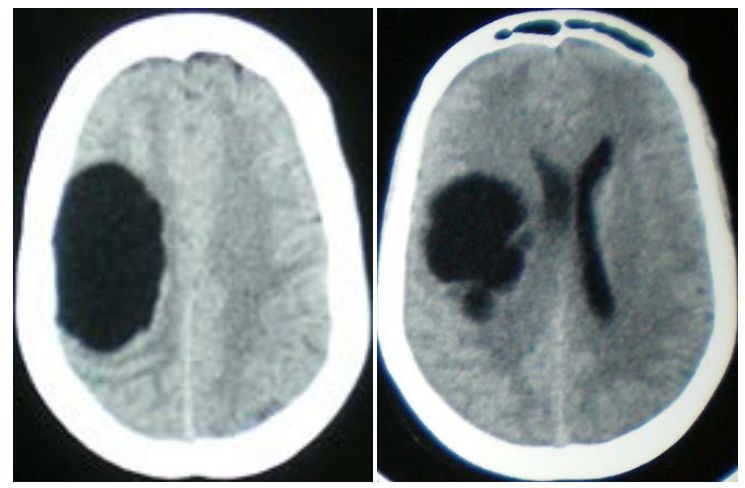

Figure 1. Preoperative CT scan showing the arachnoid cystin the right frontoparietal. 


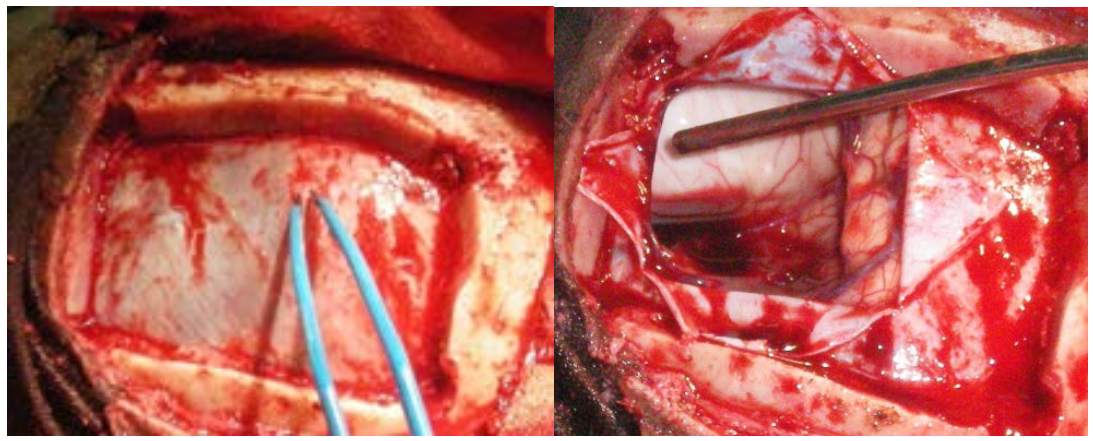

(a)

(b)

Figure 2. Operative images showing (a) craniotomy, (b) fenestration of the cyst.

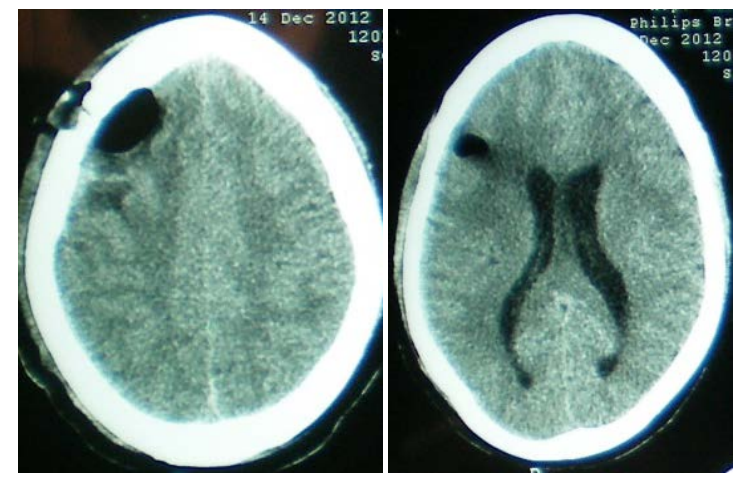

Figure 3. Post-operative CT scan showing the resolution of the cyst.

membrane that are expanded by the secretion of CSF. Arachnoid cysts are benign lesions discovered incidentally that rarely enlarge [1] [17]. Approximately $50 \%-65 \%$ of IAC occur in the middle cranial fossa [18]. IAC are often found incidentally and therefore asymptomatic. They become symptomatic via local mass effect, obstruction of CSF outflow tract, or hemorrhage into the cyst [7] [19] [20]. Although the mechanisms that drive arachnoid cyst enlargement remain unknown, it has been postulated that cysts may expand due to: 1) active secretion of CSF by the cyst wall; 2) water entry into the cyst because of osmotic pressure difference; 3) communication of the cyst with the subarachnoid space and consequent entry of CSF into the cyst either freely or by one-way valve mechanism; and 4) pulsation of intracystic CSF driven by the cardiovascular pump. Hemorrhage into an asymptomatic arachnoid cyst can be: 1) spontaneous (15\% of Sylvian arachnoid cysts), 2) due to a head injury with or without a concomitant subdural hematoma, or 3) due to aneurysmal rupture [21] [22] [23] [24]. Cases of spontaneous regression of AC have been described [17]. The signs and symptoms of arachnoid cysts vary according to their size and location. Small cysts are usually asymptomatic, requiring observation and follow up. However, larger cysts can have a mass effect on neurovascular structures, leading to neurological symptoms [13]. IAC usually present with mild and slow progressive symptoms [25]. Headaches are the most common symptom, accounting for a share of $66 \%$ [26]. Other symptoms include dizziness, nausea, vomiting, wor- 
sening of mood, mental status changes, ataxia, seizures, and hearing loss [27]. The acute neurologic symptoms in our patient are atypical for a patient with an arachnoid cyst in this localization. The exact mechanism remain unclear but could have been due to the rapidly enlargement of the cyst. Some IAC may cause obstructive hydrocephalus by blocking the outflow of CSF. Obstructive hydrocephalus is frequently seen in patients with cysts in the suprasellar localization [28]. IAC appear on both computed tomography (CT) and MRI as homogeneous, non-enhancing, well circumscribed, non-calcified, and extra-parenchymal masses with a signal identical to CSF [29] [30]. In this case, the CT scan presentation was in favor of the diagnosis of ICA. This was further confirmed by the peroperative discovery of a typical arachnoid cyst with an arachnoid membrane, which was widely opened during cyst marsupialization. The Galassi [31] classification is used to classify middle fossa cysts into three types. Type I cysts are typically asymptomatic and are present in the anterior middle cranial fossa. Type II cysts extend superiorly along the Sylvian fissure, occasionally displacing the temporal lobe. Finally, Type III cysts are very large and occupy the entire middle cranial fossa, displacing not only the temporal lobe but also disrupting the parietal and frontal lobes. There usually is an indication for surgery when there are symptoms of increased intracranial pressure, seizures, focal neurologic deficits or cognitive impairment. Surgical options include craniotomy and cyst excision, cyst-peritoneal and/or ventriculoperitoneal shunt placement, and endoscopic cyst fenestration. Location and size of symptomatic arachnoid cysts are major determinants of treatment strategy. Craniotomy and cyst marsupialization remains the most favored treatment option for Sylvian fissure cysts and other convexity cysts with are ported success rate up to $76 \%$ in one series [32] [33]. The acute onset of neurological signs and the localization of cyst prompt us to do an emergency marsupialization via craniotomy in our case.

\section{Conclusion}

Most of IAC are clinically silent. Symptomatic IAC usually present with mild and slow progressive symptoms caused by the cyst. Acute symptoms are rare and may require prompt surgical treatment.

\section{Conflicts of Interest}

The authors declare no conflicts of interest regarding the publication of this paper.

\section{References}

[1] Balsubramaniam, C., Laurent, J., Rouah, E., Armstrong, D., Feldstein, N., Schneider, S., et al. (1989) Congenital Arachnoid Cysts in Children. Journal of Pediatric Neurosciences, 15, 223-228. https://doi.org/10.1159/000120473

[2] Choi, J.U. and Kim, D.S. (1998) Pathogenesis of Arachnoid Cysts: Congenital or Traumatic? Pediatric Neurosurgery, 29, 260-266. https://doi.org/10.1159/000028733 
[3] Koutsimpelas, D., Mueller-Forell, W., Stoeter, P., Hey, O. and Mann, W.J. (2010) Arachnoid Cyst with Extraordinary Extracranial Extension in the Skull Base as a Result of an Iatrogenic Defect of the Middle Cranial Fossa Floor: Case Report and Literature Review. Journal of Cranio-Maxillofacial Surgery, 38, 284-287. https://doi.org/10.1016/j.jcms.2009.03.005

[4] Rengachary, S.S. and Watanabe, I. (1981) Ultrastructure and Pathogenesis of Intracranial Arachnoid Cysts. Journal of Neuropathology and Experimental Neurology, 40, 61-83. https://doi.org/10.1097/00005072-198101000-00007

[5] Albuquerque, F.C. and Giannotta, S.L. (1997) Arachnoid Cyst Rupture Producing Subdural Hygroma and Intracranial Hypertension: Case Reports. Neurosurgery, 41, 951-955. https://doi.org/10.1097/00006123-199710000-00036

[6] Al-Holou, W.N., Terman, S., Kilburg, C., Garton, H.J., Muraszko, K.M. and Maher, C.O. (2013) Prevalence and Natural History of Arachnoid Cysts in Adults. Journal of Neurosurgery, 118, 222-231. https://doi.org/10.3171/2012.10.JNS12548

[7] Al-Holou, W.N., Yew, A.Y., Boomsaad, Z.E., Garton, H.J., Muraszko, K.M. and Maher, C.O. (2010) Prevalence and Natural History of Arachnoid Cysts in Children. Journal of Neurosurgery: Pediatrics, 5, 578-585.

https://doi.org/10.3171/2010.2.PEDS09464

[8] Pradilla, G. and Jallo, G. (2007) Arachnoid Cysts: Case Series and Review of the Literature. Neurosurgical Focus, 22, 7. https://doi.org/10.3171/foc.2007.22.2.7

[9] Zada, G., Krieger, M.D., McNatt, S.A., Bowen, I. and McComb, J.G. (2007) Pathogenesis and Treatment of Intracranial Arachnoid Cysts in Pediatric Patients Younger than 2 Years of Age. Neurosurgical Focus, 22, E1. https://doi.org/10.3171/foc.2007.22.2.1

[10] Kandogan, T., Olgun, L., Gültekin, G., Aydar, L. and Sezgin, O. (2004) A Suprasellar Arachnoid Cyst Destructing Sphenoid Sinus: An Unusual Cause of Headache in an Elderly Female. Swiss Medical Weekly, 134, 28-29.

[11] Van der Meche, F.G.A. and Braakman, R. (1983) Arachnoid Cysts in the Middle Cranial Fossa: Cause and Treatment of Progressive and Nonprogressive Symptoms. Journal of Neurology, Neurosurgery, and Psychiatry, 46, 1102-1107. https://doi.org/10.1136/jnnp.46.12.1102

[12] Rabiei, K., Jaraj, D., Marlow, T., Jensen, C., Skoog, I. and Wikkelsø, C. (2016) Prevalence and Symptoms of Intracranial Arachnoid Cysts: A Population-Based Study. Journal of Neurology, 263, 689-694. https://doi.org/10.1007/s00415-016-8035-1

[13] Wang, C., Liu, C., Xiong, Y., et al. (2013) Surgical Treatment of Intracranial Arachnoid Cyst in Adult Patients. Neurology India, 61, 60-64. https://doi.org/10.4103/0028-3886.108013

[14] Ahn, J.Y., Chio, J.U., Yoon, S.H., Chung, S.S. and Lee, K.C. (1994) Treatment and Outcome of Intracranial Arachnoid Cysts. Journal of Korean Neurosurgical Society, 23, 194-203.

[15] Karabatsou, K., Hayhurst, C., Buxton, N., O’Brien, D.F. and Mallucci, C.L. (2007) Endoscopic Management of Arachnoid Cysts: An Advancing Technique. Journal of Neurosurgery, 106, 455-462. https://doi.org/10.3171/ped.2007.106.6.455

[16] Bright, R. (1831) Serous Cysts in Arachnoid; in Reports of Medical Cases Selected with a View of Illustrating the Symptoms and Cure of Diseases by a Reference to Morbid Anatomy. Part I. Diseases of the Brain and Nervous System. Richard Taylor, London, Vol. II, 437-449.

[17] Geissinger, J.D., Kohler, W.C., Robinson, B.W. and Davis, F.M. (1978) Arachnoid Cysts of the Middle Cranial Fossa: Surgical Considerations. Surgical Neurology, 10, 
27-33.

[18] Goswami, P., Medhi, N., Sarma, P.K. and Sarmah, B.J. (2008) Case Report: Middle Cranial Fossa Arachnoid Cyst in Association with Subdural Hygroma. The Indian Journal of Radiology and Imaging, 18, 222-223.

[19] Kumagai, M., Sakai, N., Yamada, H., Shinoda, J., Nakashima, T. and Iwama, T. (1986) Postnatal Development and Enlargement of Primary Middle Cranial Fossa Arachnoid Cyst Recognized on Repeat CT Scan. Childs Nervous System, 2, 211-215. https://doi.org/10.1007/BF00706815

[20] Lee, J.Y., Kim, J.W., Phi, J.H., Kim, S.K., Cho, B.K. and Wang, K.C. (2012) Enlarging Arachnoid Cyst: A False Alarm for Infants. Childs Nervous System, 28, 1203-1211. https://doi.org/10.1007/s00381-012-1722-Z

[21] Halani, H., Mina, M.S., Safain, G. and Heilman, C.B. (2013) Arachnoid Cyst Slit Valves: The Mechanism for Arachnoid Cyst Enlargement. Report of 5 Cases. Journal of Neurosurgery: Pediatrics, 12, 62-66. https://doi.org/10.3171/2013.4.PEDS12609

[22] Wilkinson, C.C., Wilson, K.R., Albright, A.L., Pollack, I.F. and Adelson, P.D. (2008) Congenital Arachnoid Cyst and Dandy-Walker Complex. Principles and Practice of Pediatric Neurosurgery. Thieme, New York, 162-186.

[23] Parsch, C., Kraub, J., Hofinann, E., et al. (1997) Arachnoid Cysts Associated with Subdural Haematomas and Hygromas: Analysis of 16 Cases, Long Term Follow up, and Review of the Literature. Neurosurgery, 40, 483-490.

[24] Iaconetta, G., Esposito, M., Maiuri, F., et al. (2006) Arachnoid Cyst with Intracystic Hemorrhage and Subdural Hematoma: Case Report and Literature Review. Neurological Sciences, 26, 451-455. https://doi.org/10.1007/s10072-006-0532-Z

[25] Hell, C. and Wester, K. (2006) A Population-Based Study of Intracranial Arachnoid Cysts: Clinical and Neuroimaging Outcomes Following Surgical Cyst Decompression in Children. Journal of Neurosurgery, 105, 385-390.

[26] Hell, C.A. and Wester, K. (2007) A Population Based Study of Intracranial Arachnoid Cysts: Clinical and Neuroimaging Outcomes Following Surgical Cyst Decompression in Adults. Journal of Neurology, Neurosurgery, and Psychiatry, 78, 1129-1135. https://doi.org/10.1136/jnnp.2006.107995

[27] Wojcik, G. (2016) Intracranial Arachnoid Cysts in the Clinical and Radiological Aspect. Wiadomości Lekarskie, 69, 555-559.

[28] Mattox, A., Choi, J., Leith-Gray, L., Grant, G. and Adamson, D. (2010) Guidelines for the Management of Obstructive Hydrocephalus from Suprasellar-Prepontine Arachnoid Cysts Using Endoscopic Third Ventriculocystocisternostomy. Surgical Innovation, 17, 206-216. https://doi.org/10.1177/1553350610377212

[29] Barkovich, J. and Raybaud, C. (2012) Congenital Malformations of the Brain and Skull. In: Pediatric Neuroimaging, 5th Edition, Wolters Kluwer \& Lipincott Williams \&Wilkins, Philadelphia, 524-528.

[30] Osborn, A.G., Blaser, S.I., Salzman, K.L., Provenzale, J., Castillo, M., Hedlund, G.L., et al. (1996) Diagnostic Imaging: Brain. William and Wilkins, Baltimore.

[31] Galassi, E., Tognetti, F., Gaist, G., Fagioli, L., Frank, F. and Frank, G. (1982) CT Scan and Metrizamide CT Cisternography in Arachnoid Cysts of the Middle Cranial Fossa: Classification and Pathophysiological Aspects. Surgical Neurology, 17, 363-369. https://doi.org/10.1016/0090-3019(82)90315-9

[32] Raffel, C. and McComb, J.G. (1988) To Shunt or to Fenestrate: Which Is the Best Surgical Treatment for Arachnoid Cysts in Pediatric Patients? Neurosurgery, 23, 
338-342. https://doi.org/10.1227/00006123-198809000-00009

[33] Tamburrini, G., Dal Fabbro, M. and Di Rocco, C. (2008) Sylvian Fissure Arachnoid Cysts: A Survey on Their Diagnostic Workout and Practical Management. Child $s$ Nervous System, 24, 593-604. https://doi.org/10.1007/s00381-008-0585-9 